\title{
Analysis on Causes Affecting Payment Method of Small and Micro Cross-border E-commerce
}

\author{
Xiang WU*, Jian-lin ZHANG \\ Alibaba Business School, Hangzhou Normal University, Hangzhou, China \\ ${ }^{*}$ Corresponding author
}

Keywords: Small and Micro Enterprise; Cross-border E-commerce; Payment.

\begin{abstract}
In recent years, China's cross-border e-commerce is gaining unprecedented opportunities for development under the increasing market demand. The major domestic e-commerce giants are rising rapidly, relying on their existing advantages in the cross-border e-commerce sector. In the process of development, no large and medium-sized enterprises can equal the overall export performance of small and micro enterprises. In addition, the trend of "mass entrepreneurship and innovation" has made new progress recently, and the expansion scale of small and micro cross-border e-commerce will surely be more extensive, and it will be more important for the development of the national economy and solving employment. Payment is one of the pivotal aspects of cross-border transactions and a primary consideration for any type of cross-border transaction. This paper studies the current situation of the use of small and micro-cross-border e-commerce payment methods in China, analyzes the reasons and internal needs of different payment methods of cross-border, and puts forward corresponding conclusions and suggestions. In order to regulate China's large number, wide distribution, small size and small size cross-border e-commerce, it should be incorporated into the legal supervision system as soon as possible. As a result, it provides a better reference sample for the follow-up work of small-scale cross-border e-commerce practitioners and traditional foreign trade enterprises.
\end{abstract}

\section{Overview of Small and Micro Cross-border E-commerce}

\subsection{Definition of small and micro cross-border e-commerce}

Cross-border shopping via e-commerce is growing rapidly and receiving more study by companies actively engaged in supporting international transactions A recent survey of Global Acquirers [1]. In this paper, small and micro cross-border e-commerce enterprises are defined as the things that in the field of international trade, through cross-border e-commerce trading platform, transactions are concluded, payments are settled, and goods are delivered through cross-border logistics, with an annual total export value of less than US\$3 million, which meets the criteria for the size of small and micro enterprises in China.

\subsection{Payment mode for small and micro cross-border e-commerce}

\subsubsection{Local credit card in the trading country}

For certain cross-border exports, small and micro-cross-border e-commerce companies sign financial payment agreements with banks in the place where the transaction takes place. As long as they are paid by bank card (credit card), online purchase can be completed. And, banks and payment institutions extort exorbitant amount which varies from country to country [2].

\subsubsection{Third-party payment platform}

Due to the high transaction frequency and low transaction amount, the small and micro-cross-border e-commerce business has small transaction volume, few resources and low Internet technology. Only third-party payment platforms can be selected for electronic payment.

\subsubsection{Personal foreign exchange account transfer}

In order to save costs, some small and micro enterprises adopt a payment model in which the buyer in the consumer's area pays the money to the small and micro enterprise office in the area, 
and then the office repatriates to the country. Cash on delivery, for another example, remains the dominant mode of payment in Africa and the Middle East [3].

\section{Index System Construction}

Based on the domestic scholars' key assessment factors affecting cross-border payment, this paper combines the status quo of small-scale cross-border e-commerce industry and the characteristics of cross-border e-commerce platform to confirm the evaluation system of small-scale cross-border e-commerce payment method selection:

\subsection{Economic environment}

\subsubsection{Maturity of financial environment}

The penetration rate and coverage of cross-border payment methods are the basis and premise for selecting cross-border payment methods. This factor assesses the geographical coverage and accuracy of different cross-border payment methods such as credit card payment, cash on delivery, and third-party payment platforms.

\subsubsection{E-commerce technology maturity}

The more e-commerce platforms a trading region has, the greater the popularity of Internet technology. This factor assesses the concentration of e-commerce platforms in a region and the extent to which e-commerce technologies are used.

\subsection{Social environment}

\subsubsection{Recognition of local society and office}

The recognition of local society and office is reflected in three aspects: whether the social institutions and government agencies in the trading area encourage and recognize certain payment methods, whether the local regulatory authorities have issued financial payment licenses to the payment platform, and whether the payment platform is fully aware of the payment platform. In addition, bilateral cross-border payment flows increase with the size, location and cultural similarity of the other countries [4].

\subsubsection{Payment habits and preferences of target consumer groups}

Cross-border payment patterns are different due to the payment habits, preferences and macroeconomic environment factors of target consumers, such as consumers in some countries are accustomed to credit card payments, and consumers in some countries are accustomed to paying in cash.

\subsection{Use-Cost}

\subsubsection{Capital cost}

The cost of capital includes the transaction fee, the cost of the exchange rate and so on. The handling fees for different payment methods vary, and a comprehensive comparison is required.

\subsubsection{Time cost}

Cross-border e-commerce sellers are far more difficult than domestic e-commerce sellers in terms of payment recovery. Difficulties in foreign exchange settlement, slow turnover, high withdrawal rate and exchange rate risk are all important issues that restricting cross-border e-commerce payment. New information costs may be attributable to linguistic, cultural and institutional differences and the trade costs related to the operations of e-commerce infrastructure [5].

\subsection{The competitiveness of the payment method itself}

\subsubsection{Platform stability, security and ease of use}

As the most critical link in the transaction process, the stability and security of payment become the most important consideration.

\subsubsection{Binding degree to large platforms}


As an indispensable part of large-scale platform transactions, payment has developed its own payment methods on many cross-border platforms or institutions.

\section{Research Method}

Due to the small size, wide distribution and weak voice of small and micro cross-border e-commerce, it is difficult to find detailed data and research in the existing social survey data. Therefore, this paper chose to use the questionnaire survey. In the form of interviews with small and micro cross-border e-commerce practitioners, deepening the current living conditions of such groups, through multi-angle information collection, comprehensive understanding the reasons and effects of choosing different payment methods for micro-cross-border e-commerce.

A total of 397 questionnaires were distributed. After eliminating invalid questionnaires such as non-small and micro cross-border e-commerce practitioners, omissions, repeated answers and so on, 204 valid questionnaires were returned with an effective rate of $51 \%$. The industry distribution of the respondents is as follows: the questionnaire covers enterprises covering garment accessories, beauty care, electronic products, furniture, gifts and toys, shoes, bags, office supplies, etc. Due to the characteristics of small and micro cross-border e-commerce retail transactions, the scale of the survey enterprises is mainly limited to 10-50 employees, of whom 10-30 employees accounted for $43 \%, 30-50$ employees for $57 \%$. The annual sales of enterprises surveyed accounted for $5.88 \%$ of the total annual sales below $¥ 500,000$ (RMB), $25.98 \%$ of the total sales of $¥ 500,000$ to 1 million, $28.92 \%$ of the total sales of $¥ 1$ million to $¥ 3$ million, $20.59 \%$ of the total sales of $¥ 3$ million to $¥ 5$ million, $13.24 \%$ of the total sales of $¥ 5$ million to $¥ 10$ million, $2.45 \%$ of the total sales of $¥ 10$ million to $¥ 20$ million, and $2.94 \%$ upon $¥ 20$ million. Widely used third party platform rankings are China Manufacturing Network, Amazon, Ali Express, eBay, DHgate.com, Wish and Osell. From the point of view of exporting countries, the regions with the largest exports are the United States, South Korea, Japan, Britain, Russia, Canada, France, Brazil and so on.

\section{Questionnaire Survey Results and Modeling Analysis}

According to the results of 204 valid questionnaires, the cross-border payment methods most commonly used by consumers when conducting cross-border transactions on small-scale cross-border e-commerce platforms are third-party payment tools, including Apple Pay, PayPal, Alipay, Google chechout, etc. The choice of this type of payment method reached $65.69 \%$. The second is to use personal foreign exchange account transfer, accounting for $20.59 \%$. In addition, $13.72 \%$ of the surveyed companies selected local credit cards from trading countries.

\subsection{Variables selection and model setting}

According to the index system constructed in the previous section, this part carries out with 204 observations to perform descriptive statistics, mean analysis and multivariate logistic regression analysis on the observed values to study the influence degree and influence direction of explanatory variables on the interpreted variables.

\subsubsection{Descriptive statistics}

In order to understand the basic characteristics of the data, descriptive statistics are performed to understand the basic situation of the data, and correlative descriptive statistics are made to the variable data, including observations, minimum, maximum, mean and standard deviation.

Table 1. Frequency analysis

\begin{tabular}{c|c|c|c}
\hline $\mathrm{y}$ & Freq. & Percent & Cum. \\
\hline 1 & 134 & 65.69 & 65.69 \\
\hline 2 & 28 & 13.72 & 79.41 \\
\hline 3 & 42 & 20.59 & 100 \\
\hline Total & 204 & 100 & \\
\hline
\end{tabular}


In Table 1, 1 of the corresponding to $\mathrm{y}$ is a third-party payment instrument, 2 is a local credit card of the trading country, and 3 is a personal foreign exchange account transfer. The proportion of respondents who chose third-party payment instruments was $65.69 \%$, the proportion of local credit cards in the trading countries was $13.72 \%$, and the proportion of respondents using personal foreign exchange accounts was $20.59 \%$. It can be seen that, relatively speaking, third-party payment instruments are used most frequently in platform transactions of small and micro-cross-border e-commerce.

Table 2. Descriptive statistics

\begin{tabular}{cccccc}
\hline Variable & Obs & Mean & Std. Dev. & Min & Max \\
\hline x1 & 204 & 3.6716 & 1.0387 & 0.0000 & 5.0000 \\
x2 & 204 & 3.8627 & 0.9979 & 0.0000 & 5.0000 \\
x3 & 204 & 3.7451 & 1.0189 & 0.0000 & 5.0000 \\
x4 & 204 & 3.7108 & 1.0314 & 0.0000 & 5.0000 \\
x5 & 204 & 3.3431 & 1.1053 & 0.0000 & 5.0000 \\
x6 & 204 & 3.8284 & 1.0434 & 0.0000 & 5.0000 \\
x7 & 204 & 3.8088 & 1.1176 & 0.0000 & 5.0000 \\
x8 & 204 & 3.8578 & 1.0144 & 1.0000 & 5.0000 \\
\hline
\end{tabular}

The descriptive analysis of the survey data shows that the mean values of all variables are higher than 3.5 , so the respondents' satisfaction with various variables is higher.

\subsubsection{Mean analysis}

By analyzing the existing survey of 204 questionnaires, the average scores of each index are calculated, which is the most intuitive reflection of the importance of the factors that determine the different payment methods for small and micro cross-border e-commerce in the eyes of the respondents.

$$
\begin{aligned}
& \overline{\mathrm{x}} 1=\sum_{\mathrm{k}=1}^{\mathrm{n}}\left(\mathrm{x}_{\mathrm{ki}}\right) / \mathrm{n}=\sum_{\mathrm{k}=1}^{\mathrm{n}=204}\left(\mathrm{x}_{\mathrm{ki}}\right) / 204=3.6716 \\
& \overline{\mathrm{x}} 2=\sum_{\mathrm{k}=2}^{\mathrm{n}}\left(\mathrm{x}_{\mathrm{ki}}\right) / \mathrm{n}=\sum_{\mathrm{k}=204}^{\mathrm{n}=204}\left(\mathrm{x}_{\mathrm{ki}}\right) / 204=3.8628 \\
& \overline{\mathrm{x}} 3=\sum_{\mathrm{k}=3}^{\mathrm{n}}\left(\mathrm{x}_{\mathrm{ki}}\right) / \mathrm{n}=\sum_{\mathrm{k}=204}^{\mathrm{n}=204}\left(\mathrm{x}_{\mathrm{ki}}\right) / 204=3.7451 \\
& \overline{\mathrm{x}} 4=\sum_{\mathrm{k}=4}^{\mathrm{n}}\left(\mathrm{x}_{\mathrm{ki}}\right) / \mathrm{n}=\sum_{\mathrm{k}=4}^{\mathrm{n}=204}\left(\mathrm{x}_{\mathrm{ki}}\right) / 204=3.7108 \\
& \overline{\mathrm{x}} 5=\sum_{\mathrm{k}=5}^{\mathrm{n}}\left(\mathrm{x}_{\mathrm{ki}}\right) / \mathrm{n}=\sum_{\mathrm{k}=5}^{\mathrm{n}=204}\left(\mathrm{x}_{\mathrm{ki}}\right) / 204=3.3431 \\
& \overline{\mathrm{x}} 6=\sum_{\mathrm{k}=6}^{\mathrm{n}}\left(\mathrm{x}_{\mathrm{ki}}\right) / \mathrm{n}=\sum_{\mathrm{k}=6}^{\mathrm{n}=204}\left(\mathrm{x}_{\mathrm{ki}}\right) / 204=3.8284 \\
& \overline{\mathrm{x}} 7=\sum_{\mathrm{k}=7}^{\mathrm{n}}\left(\mathrm{x}_{\mathrm{ki}}\right) / \mathrm{n}=\sum_{\mathrm{k}=7}^{\mathrm{n}=204}\left(\mathrm{x}_{\mathrm{ki}}\right) / 204=3.8088 \\
& \overline{\mathrm{x}} 8=\sum_{\mathrm{k}=8}^{\mathrm{n}}\left(\mathrm{x}_{\mathrm{ki}}\right) / \mathrm{n}=\sum_{\mathrm{k}=204}^{\mathrm{n}=204}\left(\mathrm{x}_{\mathrm{ki}}\right) / 204=3.8578
\end{aligned}
$$

From the above average results, the averages are arranged respectively in descending order of $\mathrm{x} 2$, $\mathrm{x} 8, \mathrm{x} 6, \mathrm{x} 7, \mathrm{x} 3, \mathrm{x} 4, \mathrm{x} 1, \mathrm{x} 5$. That is to say, the main factors affecting the choice of different cross-border payment modes for small and micro enterprises in order of importance are ordered as follows: e-commerce technology maturity, platform binding degree, time cost, platform ease of use, social recognition, target group payment habits, financial environment maturity, and capital costs.

\subsubsection{Modeling analysis}

On the basis of referring to domestic and foreign literature, the author chose eight factors to build the model as follows:

$$
Y=\alpha_{0}+\alpha_{1} X_{1}+\alpha_{2} X_{2}+\alpha_{3} X_{3}+\alpha_{4} X_{4}+\alpha_{5} X_{5}+\alpha_{6} X_{6}+\alpha_{7} X_{7}+\alpha_{8} X_{8}+\varepsilon_{i t}
$$

The constant term is a coefficient term and a random error term. The variable of X1 represents financial environment maturity, X2 stands for e-commerce technology maturity, X3 represents social acceptance, X4 represents payment habits, X5 represents capital cost, X6 represents time cost, $\mathrm{X} 7$ represents platform stability, and $\mathrm{X} 8$ represents third-party platform binding. 
Since the values of the interpreted variables in the survey data are not continuous, the sample data is selected for analysis using a multivariate logistic regression method. This section analyzes the impact of credit card payments and individual foreign exchange account transfer payments. The corresponding 1 in Table 3 represents the third-party payment instrument, 2 represents the local credit card of the trading country and 3 stands for the transfer of individual foreign exchange accounts.

Table 3. Multivariate logistic analysis

\begin{tabular}{|c|c|c|c|c|c|}
\hline & $\mathrm{y}$ & Coef. & Std.Err. & $\mathrm{Z}$ & $\mathrm{P}>\mathrm{Z}$ \\
\hline 1 & $\begin{array}{c}\text { (base } \\
\text { outcome) }\end{array}$ & & & & \\
\hline \multirow[t]{9}{*}{2} & $\mathrm{x} 1$ & 0.1973 & 0.2710 & 0.7300 & 0.4670 \\
\hline & $\mathrm{x} 2$ & -0.2616 & 0.2458 & -1.0600 & 0.2870 \\
\hline & $\mathrm{x} 3$ & -0.0140 & 0.2402 & -0.0600 & 0.9540 \\
\hline & $\mathrm{x} 4$ & -0.2402 & 0.2542 & -0.9400 & 0.3450 \\
\hline & $\mathrm{x} 5$ & -0.1759 & 0.1979 & -0.8900 & 0.3740 \\
\hline & $x 6$ & -0.2422 & 0.2399 & -1.0100 & 0.3130 \\
\hline & $\mathrm{x} 7$ & -0.0119 & 0.2346 & -0.0500 & 0.9600 \\
\hline & $\mathrm{x} 8$ & 0.0288 & 0.2176 & 0.1300 & 0.8950 \\
\hline & _cons & 1.0254 & 1.1459 & 0.8900 & 0.3710 \\
\hline \multirow[t]{9}{*}{3} & $\mathrm{x} 1$ & 0.1943 & 0.2319 & 0.8400 & 0.4020 \\
\hline & $\mathrm{x} 2$ & 0.0930 & 0.2162 & 0.4300 & 0.6670 \\
\hline & $\mathrm{x} 3$ & 0.1113 & 0.2181 & 0.5100 & 0.6100 \\
\hline & $\mathrm{x} 4$ & 0.2645 & 0.2321 & 1.1400 & 0.2550 \\
\hline & $\mathrm{x} 5$ & -0.1073 & 0.1866 & -0.5700 & 0.5650 \\
\hline & $x 6$ & $-0.3890 *$ & 0.2068 & -1.8800 & 0.0600 \\
\hline & $\mathrm{x} 7$ & $-0.4018 * *$ & 0.1968 & -2.0400 & 0.0410 \\
\hline & $\mathrm{x} 8$ & -0.1211 & 0.2000 & -0.6100 & 0.5450 \\
\hline & cons & 0.1348 & 1.1152 & 0.1200 & 0.9040 \\
\hline
\end{tabular}

Note: $* * *, * *, *$ indicates significance at the significant level of $0.01,0.05$, and 0.1 respectively.

From the above regression results, it can be seen that among the factors that influence the choice of local credit card payment and third-party payment, the value of $x 1-x 8$ is greater than 0.1 . That is to say, the eight factors listed at present have no significant impact on the choice of the two payment methods. Compared with third-party payment, the payment of individual foreign exchange account transferring has some advantages. The time cost (x6) and platform usability (x7) of the payment of individual foreign exchange account transferring are significantly lower than those of third-party payment at the significant level of 0.1 . In another word, the time cost of payment of individual foreign exchange account transferring is lower, and the platform usability is also lower than that of third-party payment platforms.

\section{Conclusion and Suggestions}

According to 204 valid survey data, $65.69 \%$ of small and micro cross-border e-commerce companies choose third-party payment tools as the payment platform. It's related to the technical level of small and micro enterprises themselves, and it is closely to the group relying on third-party e-commerce platform for procurement and promotion. The payment method of large-scale third-party e-commerce platform determines the choice of payment methods for small and micro enterprises, which can only passively choose to accept the existing payment body. But it also promotes the standardization and unification of the payment environment. Finally some suggestions and measures are proposed: 
The government should vigorously promote the cross-border payment system of RMB, and improve the legal supervision system at the same time.

Be widely known, fiscal policy, especially automatic stabilizers, seems to play a significant role [6]. First of all, we should speed up the establishment of an independent cross-border RMB clearing system, and get rid of the dependence on overseas SWIFT system. In the process of construction, we should follow the principles of standardization and internationalization, and achieve compatibility with overseas clearing system. In addition, we should improve the current large-scale payment system for cross-border RMB settlement, and greatly extend the working time of the large-scale payment system for cross-border RMB. What's more, we should build a hybrid payment system combining full real-time settlement and delayed net settlement. At last, we should improve the single queuing system of "first in first out" and establish flexible and efficient queuing rules.

Bank institutions should provide port and channel services and actively promote cross-border payment and transfer services in some countries and regions.

When investing abroad, banks take several risks, such as interest rate, exchange rate and inflation risks, which depend on current and future monetary policy [7]. In order to adapt to the rapid growth of cross-border RMB settlement business, UnionPay should actively provide cross-border B2C payment solutions for domestic and foreign exchange payment business qualifications, and provide cross-border B2C payment and receipt solutions for Chinese import and export enterprises, based on cross-border RMB and foreign exchange payment business qualifications.

\section{References}

[1] Guy H. Gessner, Coral R. Snodgrass. Designing e-commerce cross-border distribution networks for small and medium-size enterprises incorporating Canadian and U.S. trade incentive programs [J]. Research in Transportation Business \& Management, 2015 (16): 84-94.

[2] Sylvia Mercado-Kierkegaard. Payments in the internal market and the new legal framework EU law: harmonising the regulatory regime for cross-border payment services [J]. Computer Law and Security Review, 2007, 23 (2): 177-187.

[3] International Trade Centre. Bringing SMEs onto the E-commerce Highway. 2017. Information on https://doi.org/10.18356/5bf5c218-en

[4] Simonetta Rosati, Stefania Secola. Explaining cross-border large-value payment flows: Evidence from TARGET and EURO1 data [J]. Journal of Banking \& Finance, 2006 (30): 1753-1782.

[5] Estrella Gomez-Herrera , Bertin Martens , Geomina Turlea. The drivers and impediments for cross-border e-commerce in the EU [J]. Information Economics and Policy, 2014 (28) 83-96.

[6] Letizia Montinaria, Livio Straccab. Trade, finance or policies: What drives the cross-border spill-over of business cycles? [J]. Journal of Macroeconomics, 2016 (49): 131-148.

[7] S. Eichler, H.C.N. Littke, L. Tonzer. Central Bank Transparency and Cross-border Banking [J]. Journal of International Money \& Finance, 2017 (74): 1-30. 